\title{
Investigation of influence of thermal coefficients on 2-D WH/TS OCDMA code propagation in optical fiber
}

\author{
T.B. Osadola ${ }^{1}$, S.K. Idris ${ }^{1}$, I. Glesk ${ }^{1}$, W.C. Kwong ${ }^{2}$ \\ 1. Department of Electronic and Electrical Engineering, University of Strathclyde, Glasgow \\ 2. Hofstra University, Hempstead. USA.
}

In this paper we present an extension of our previous investigation [1] of the effect of environmental temperature variation on the bit error rate (BER) performance of multiwavelength 2- dimensional wavelength hopping time spreading optical code division multiple access (2D-WH/TS OCDMA) signals that utilises picosecond pulses for code formation. Using equations already derived in [1] for modelling the effects of temperature variation on autocorrelation signal resulting from the decoding of an incoherent 2D-WH/TS OCDMA encoded signal which consists of $w$ wavelength pulses each having a pulsewidth of $\tau$ after propagating in $\mathrm{L}(\mathrm{Km})$ of fibre, we arrive at the expression for the envelope of the resulting autocorrelation peak $\mathrm{S}_{\mathrm{t}}$.

$$
S_{t}=\sum_{k=0}^{w-1} P_{p} \exp \left\{-2.77\left[\frac{t-k\left[D_{t e m p} \times \Delta T \times \Delta \Lambda \times L\right]}{\tau-\left[D_{\text {temp }} \times \Delta T \times \Delta \lambda \times L\right]}\right]^{2}\right\}
$$

$D_{\text {temp }}\left(\mathrm{ps} / \mathrm{nm} \cdot \mathrm{km} /{ }^{\circ} \mathrm{C}\right)$ is the thermal coefficient of the fiber [2,3], $\Delta T\left({ }^{\circ} \mathrm{C}\right)$ is the average change in temperature experienced by transmission fiber, $\Delta \Lambda(\mathrm{nm})$ is the spectral spacing between 2D-WH/TS OCDMA code wavelengths pulses, and $\Delta \lambda(\mathrm{nm})$ is the pulse spectral line width of each wavelength pulse within the code.

Having obtained the maximum possible autocorrelation peak $S_{t}$ for each degree of temperature change, we analysed the effect of this reduction in $S_{t}$ with respect to temperature variation by substituting $\mathrm{S}_{t}$ for th in the equation for Pe (BER) as previously derived in [1] and we obtain the equation below

$$
P_{e}=\frac{1}{2} \sum_{j=0}^{\text {St }}(-1)^{\mathrm{j}}\left(\begin{array}{c}
w \\
j
\end{array}\right)\left(1-\frac{j\left(\frac{w}{2 \cdot N_{c}}\right)}{w}\right)^{K-1}
$$

Figure 1 shows the envelope of $\mathrm{S}_{\mathrm{t}}$ for an 8 wavelength 2D-WH/TS OCDMA signal after propagation in a $10 \mathrm{~km}$ optical fibre link $\left(D_{\text {temp }}=-0.0025 \mathrm{ps} / \mathrm{nm} \cdot \mathrm{km} /{ }^{\circ} \mathrm{C}, \Delta \Lambda=0.8 \mathrm{~nm}\right.$ and $\Delta \lambda=1.4 \mathrm{~nm}, \mathrm{~N}_{\mathrm{c}}=$ code length $)$ with initial pulsewidth of 2 ps. Three different scenarios have been illustrated in the figure for $\Delta \mathrm{T}=0,10$ and 20 degrees respectively.

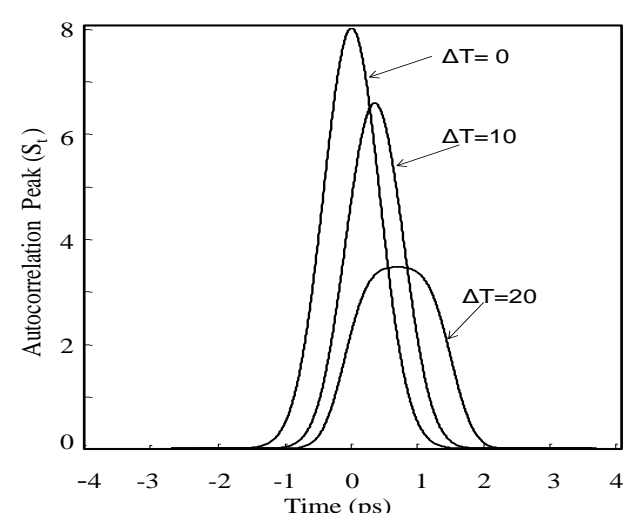

Fig. 1. Maximum obtainable autocorrelation peak $\left(S_{t}\right)$ as $\Delta$ T increases over a $10 \mathrm{~km}$.

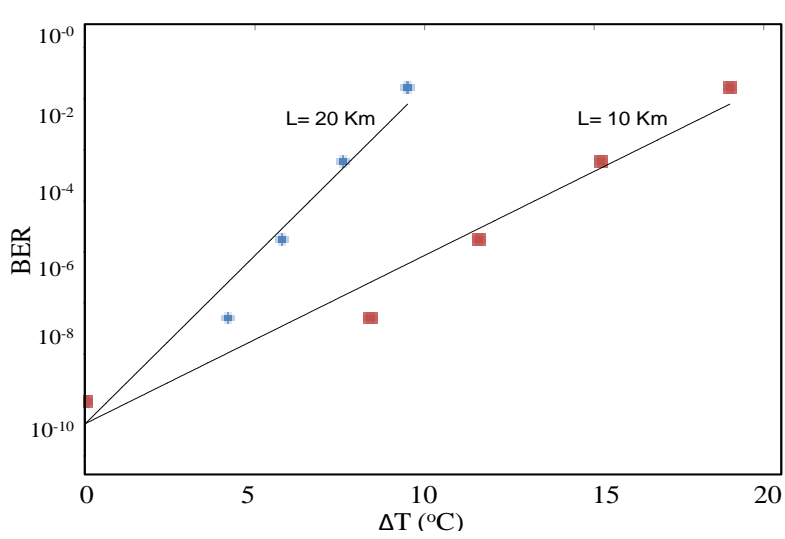

Fig. 2. Minimum obtainable BER as $\triangle T$ increases over a 10 $\mathrm{km}$ and $20 \mathrm{~km}$ link respectively with 32 simultaneous users.

To evaluate the effect of the $\Delta \mathrm{T}$ induced reduction in $\mathrm{S}_{\mathrm{t}}$, the minimum possible bit error rate performance for $\mathrm{K}=32$ simultaneous users at $2.4 \mathrm{~Gb} / \mathrm{s}$ data rate was recorded from calculations obtained using Eq. 2 for $\Delta \mathrm{T}$ between 0 and $20^{\circ} \mathrm{C}$ over a $10 \mathrm{~km}$ and $20 \mathrm{~km}$ fiber optic link. The results are presented in Figure 2 . We found that trade-offs must be made between number of simultaneous users and transmission distance in order to maintain performance.

\section{References}

[1] T. Osadola, S. Idris, I. Glesk, and W. Kwong, "Effect of Variations in Environmental Temperature on 2D-WH/TS OCDMA Code Performance," J. Opt. Commun. Netw. 5, 68-73 (2013).

[2] G. Ghosh, M. Endo, and T. Iwasaki, "Temperature-dependent Sellmeier coefficients and chromatic dispersions for some optical fiber glasses," IEEE J. Light. Technol., 12, pp.1338-1342 (1994).

[3] Ji, H.C.; Lee, J.H.; Chung, Y.C.; "System outage probability due to dispersion variation caused by seasonal and regional temperature variations," Optical Fiber Communication Conference, 2005. Technical Digest. OFC/NFOEC, 1, 3. (2005) 